Meta

Journal des traducteurs

Translators' Journal

\title{
TOURNIER, Jean (1991) : Structure lexicales de l'anglais. Guide alphabétique, Paris, Nathan, Collection Nathan-Université, 190
} p.

\section{André Clas}

Volume 38, numéro 2, juin 1993

URI : https://id.erudit.org/iderudit/002259ar

DOI : https://doi.org/10.7202/002259ar

Aller au sommaire du numéro

Éditeur(s)

Les Presses de l'Université de Montréal

ISSN

0026-0452 (imprimé)

1492-1421 (numérique)

Découvrir la revue

Citer ce compte rendu

Clas, A. (1993). Compte rendu de [TOURNIER, Jean (1991) : Structure lexicales de l'anglais. Guide alphabétique, Paris, Nathan, Collection Nathan-Université, 190 p.] Meta, 38(2), 349-349. https://doi.org/10.7202/002259ar d'utilisation que vous pouvez consulter en ligne.

https://apropos.erudit.org/fr/usagers/politique-dutilisation/ 


\section{Comptes rendus}

TOURNIER, Jean (1991): Structures lexicales de l'anglais. Guide alphabétique, Paris, Nathan, Collection Nathan-Université, 190 p.

Ce livre, comme le précise l'auteur, appartient à un tryptique. En effet, le volet central est constitué par l'excellent ouvrage Introduction à la lexicogénétique de l'anglais contemporain (1985), Paris-Genève, Champion-Slatkine, 517 p. (voir Meta 34-4: 771), le deuxième volet, tout aussi intéressant, est formé par le Précis de lexicologie anglaise (1988), Paris, Nathan, 208 p. (voir Meta 34-4 : 771). L'auteur a donc complété admirablement sa tâche avec ce guide qui présente par ordre alphabétique les mots clés de la lexicologie. On y trouve environ cinq cents notions de lexicologie bien définies et aussi bien exemplifiées. Au fond, l'auteur nous donne un dictionnaire de lexicologie valable pour de nombreuses langues, même si les exemples donnés sont essentiellement tirés de l'anglais. Les entrées sont en français et sont suivies de l'équivalent anglais: c'est donc aussi un guide bilingue. Bien mieux, lorsque l'entrée est un hyperonyme, en plus de fournir tous les renseignements pertinents sur celui-ci, on donne aussi les hyponymes qui se retrouvent dans le même champ sémantique. Ainsi, dans l'article dictionnaire, on trouve non seulement une définition, mais aussi des entrées secondaires pour les divers types de dictionnaire - bien sûr on pourrait multiplier la typologie —, mais encore des renvois pertinents, tels que adresse, définition, entrée, lexicographie, mot-vedette, etc. Cette façon de faire est d'une utilité didactique incommensurable. Dans certains cas, l'auteur signale les lacunes du français, explique la notion et décortique les équivalents possibles : voir buzz. phrase, buzzword (m'as-tu-vuisme), catch-phrase, catchword, vogue word.

Il faut savoir gré à l'auteur d'avoir préparé avec tout le soin voulu ces trois ouvrages qui comblent une lacune certaine et donnent au lecteur la «curiosité» du lexique de l'anglais et aussi des autres langues. 